\title{
An unusual presentation of pediatric osteoblastoma in a patient with Klippel-Trenaunay-Weber syndrome: case report
}

\author{
Scott A. Wallace, MD, ${ }^{1}$ Romeo C. Ignacio, MD, ${ }^{4}$ Arnett Klugh, MD, ${ }^{2}$ Gregory Gates, DO, ${ }^{3}$ and \\ Marion C. W. Henry, MD, MPH ${ }^{4}$ \\ 'Department of Neurosurgery, Walter Reed National Military Medical Center, Bethesda, Maryland; and Departments of \\ ${ }^{2}$ Neurosurgery, ${ }^{3}$ Pathology, and ${ }^{4}$ Surgery, Naval Medical Center San Diego, California
}

\begin{abstract}
Osteoblastoma is an uncommon primary bone tumor that usually presents as a painful lesion in a long bone or in the spine. Osteoblastoma has been reported only twice in the literature in conjunction with systemic fibromatosis. The authors report the case of an 8-year-old girl with suspected Klippel-Trenaunay-Weber syndrome, a rare syndrome of systemic fibromatosis, who presented with a painless thoracic rib lesion that was found to be an osteoblastoma.
\end{abstract}

http://thejns.org/doi/abs/10.3171/2014.11.PEDS13478

KEY WORDS osteoblastoma; pediatric; Klippel-Trenaunay-Weber syndrome; rib; spine; oncology

$\mathrm{O}$ STEOBLASTOMA is a rare primary bone tumor that usually presents as a painful bony lesion. A few cases have been reported in association with systemic fibromatosis. In this case report, we present the unusual case of an 8-year-old girl with suspected KlippelTrenaunay-Weber (KTW) syndrome who presented with a painless rib mass that was found to be an osteoblastoma.

\section{Case Report}

\section{History and Presentation}

This 8-year-old girl with suspected KTW syndrome presented with the discovery of a painless thoracic back mass during a workup for neurofibromatosis Type 1. On physical examination the patient was found to have multiple café-au-lait spots and capillary hemangiomas as well as a soft subcutaneous mass in the region of one of her café-au-lait spots. As this mass was nondiscrete on examination, an MRI study was obtained (Fig. 1). This study demonstrated an incidental finding of an enhancing expanding lytic lesion of the left sixth thoracic rib. The lesion was further evaluated by CT scanning (Fig. 2); a subsequent CT-guided fine-needle aspiration was performed and demonstrated osteoblastoma. Given the change of the lesion on interval imaging and the concern that this change could represent malignant degeneration, the decision was made to resect the expanding lesion. Furthermore, with no re- ports of osteoblastoma associated with KTW, we did not know if it would have a higher chance of malignant degeneration.

\section{Operation and Postoperative Course}

$\mathrm{CT}$ localization of the lesion was performed in advance of the surgical procedure for preoperative planning. On the day of surgery, the patient was positioned in a lateral decubitus position, and a vertical midline incision was made from the level of T-2 to T-8. The paraspinal muscles were mobilized off the posterior aspect of the spinal column until the rib articulation and the left T- 6 transverse process were identified. After mobilizing the paraspinal muscles 3 $\mathrm{cm}$ more laterally, we could clearly see the abnormality of the left transverse process. The bone was incised using a rongeur. Upon entry into the bony process of the left transverse process of T-6, there was clearly abnormal tissue. A portion of this was sent for pathological evaluation, and the frozen review was suggestive of osteoblastoma.

The left transverse process was then excised until normal-appearing bony tissue was identified, which resulted in complete excision of the transverse process. The spinal nerve was preserved. In addition, the neurovascular bundle of the sixth rib was preserved. The left sixth rib was then resected from the junction with the spinal column laterally for $3 \mathrm{~cm}$.

Postoperative pathological examination of the surgical

ABBREVIATION KTW = Klippel-Trenaunay-Weber.

SUBMITTED November 5, 2013. ACCEPTED November 3, 2014.

INCLUDE WHEN CITING Published online March 13, 2015; DOI: 10.3171/2014.11.PEDS13478.

DISCLOSURE The authors report no conflict of interest. The views expressed in this article are those of the authors and do not necessarily reflect the official policy or position of the Department of the Navy, Department of Defense, or the United States Government. 

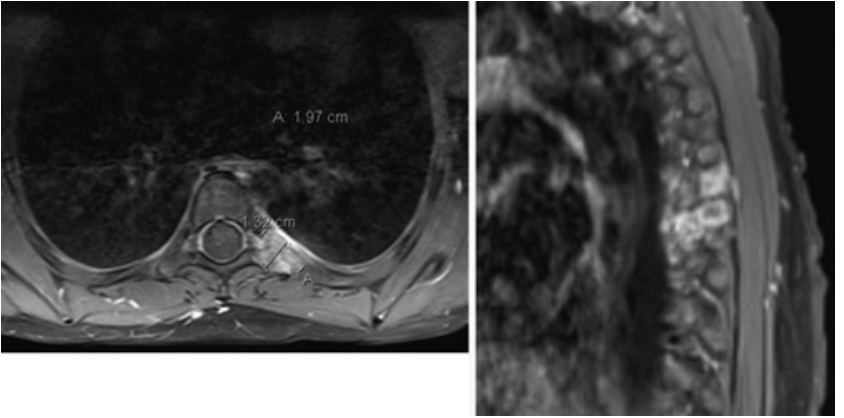

FIG. 1. Axial (left) and sagittal (right) T1-weighted postcontrast MR images obtained during the initial imaging study.

specimen demonstrated a hypercellular lesion with irregular osteoid and osteoblastic rimming. The osteoblasts were cytologically bland with no mitoses or atypia, consistent with an osteoblastoma (Fig. 3).

After surgery, the patient was initially admitted to the pediatric intensive care unit for close observation and pain control. A multi-orifice catheter (On-Q, Kimberly-Clark) was placed intraoperatively for postoperative pain control. On postoperative Day 1 the patient was transferred to the floor, and her Foley catheter was removed without difficulty. By postoperative Day 3 she was tolerating a regular diet and was up, moving, and playing on the ward comfortably.

At her 1-month postoperative follow-up visit, the patient had no pain, had no residual paresthesias at the surgical site, was neurologically intact, and had returned to all her normal activities. The results of surveillance CT and MRI studies obtained at 3 months' follow-up were normal.

\section{Discussion}

The differential diagnosis of a benign primary bone tumor includes aneurysmal bone cyst, chondroma, enchondroma, eosinophilic granuloma, fibrous dysplasia, hemangioma, osteoid osteoma, and osteoblastoma. ${ }^{13,18}$ Osteoblastomas account for approximately $1 \%$ of all primary bone neoplasms and $3 \%$ of benign primary bone neoplasms.1,16 These lesions are one-fourth to one-tenth as common as osteoid osteomas from which they can be difficult to differentiate clinically. ${ }^{3,8}$ Ninety percent of cases occur during the first 2 decades of life, with a peak incidence between the ages of 10 and 20 years., ${ }^{1,9,17}$ There is a male predominance (male to female ratio of 1.434.7:1). ${ }^{1,4,5,9,18}$ Osteoblastoma most commonly presents in the long bones and spine, with sporadic involvement of the mandible, maxilla, sternum, ribs, calvaria, and small bones of the hand.7,8,15,16,19 Patients with osteoblastoma typically present due to pain, and the lesions are only palpable in $50 \%$ of cases. ${ }^{1,9}$ Rare malignant degeneration to osteosarcoma has been reported. ${ }^{8}$

Our patient's presentation with an incidental nonpainful lesion identified on imaging is an uncommon presentation for osteoblastoma; $80 \%-100 \%$ of patients with osteoblastoma present with pain.,7,9 Rib lesions are also uncommon and constitute only $5 \%$ of osteoblastomas. . $^{2,12,19}$ Optimal management of these cases is uncertain, as this is typically a benign lesion. Resection is usually performed because of pain or neurological sequelae, neither of which
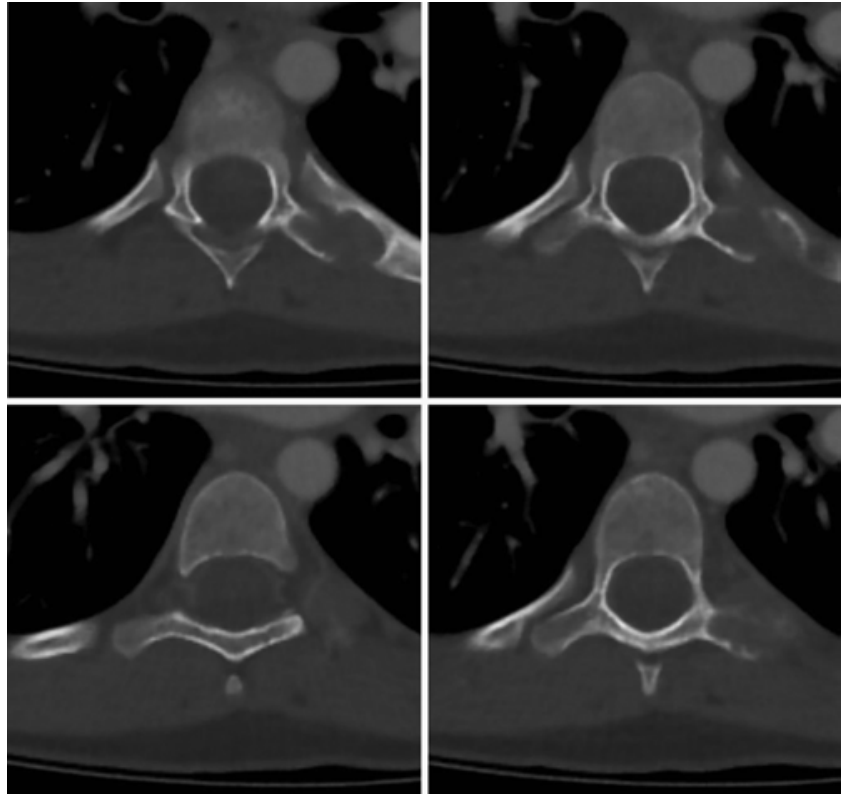

FIG. 2. Preoperative CT scans: selected axial slices through the lesion (clockwise from upper left, superior to inferior).

was present in our patient. Medical management has been tried successfully in select subsets of patients. 5 .9 Surgical therapy, including radio-ablation, complete resection, and radical resection with adjuvant radiotherapy, has been described. ${ }^{4,15}$ However, the optimal surgical management and risk stratification are also unknown, although resection is standard. ${ }^{15}$ Surgical therapy is definitely indicated for lesions concerning for malignant transformation, for pain, or for neurological deficits resulting from the lesion. In discussion with our patient's parents, we were concerned that the patient's tumor was at elevated risk of malignant degeneration due to the unusual location, presentation, and expansile character of the lesion; therefore, we advised resection.

Syndromes of systemic fibromatosis have not been clearly associated with osteoblastoma. There are only 2 reports in the literature of osteoblastoma occurring in patients with syndromes of systemic fibromatosis or fibromatosis of the soft tissues. The first report described a mandible lesion in a 60-year-old patient with Gardner's syndrome, and the second described a 30-year-old female with a left femur osteoblastoma and soft-tissue fibromatosis. ${ }^{8,16}$ Klippel-Trenaunay-Weber (KTW) syndrome is a rare syndrome of systemic fibromatosis comprising limb, soft tissue and bony hemihypertrophy, vascular staining of the skin, varicose veins, and lymphatic malformations. ${ }^{6}$ Specific genetic and biomolecular anomalies contributing to the condition have not been well elucidated, although multiple suspect genes and cohorts have been studied. ${ }^{14}$ One target gene $V G 5 Q$ (PEG3) under investigation is a known angiogenesis factor that has been associated with tumor suppressor defects in malignancies, including glioma, angiosarcoma, and ovarian cancer. ${ }^{5,10,11,14}$ To our knowledge there has been no description of an association between KTW syndrome and osteoblastoma in the literature. However, given the rarity of KTW syndrome, the true incidence may be masked. 

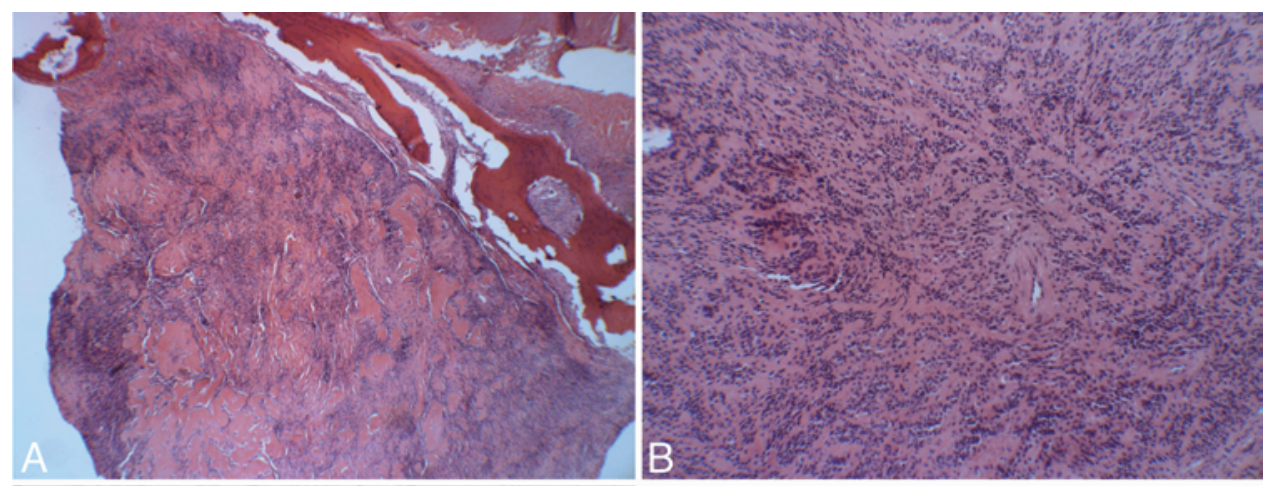

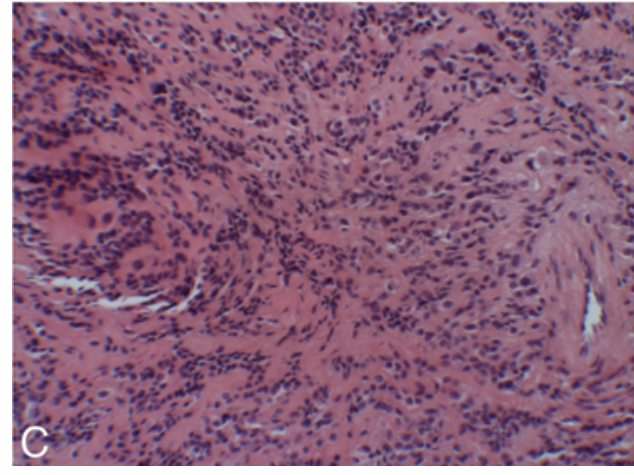

\section{References}

1. Arkader A, Dormans JP: Osteoblastoma in the skeletally immature. J Pediatr Orthop 28:555-560, 2008

2. Berry M, Mankin H, Gebhardt M, Rosenberg A, Hornicek F: Osteoblastoma: a 30-year study of 99 cases. J Surg Oncol 98:179-183, 2008

3. Burn SC, Ansorge O, Zeller R, Drake JM: Management of osteoblastoma and osteoid osteoma of the spine in childhood. J Neurosurg Pediatr 4:434-438, 2009

4. Della Rocca C, Huvos AG: Osteoblastoma: varied histological presentations with a benign clinical course. An analysis of 55 cases. Am J Surg Pathol 20:841-850, 1996

5. Feng W, Marquez RT, Lu Z, Liu J, Lu KH, Issa JP, et al: Imprinted tumor suppressor genes ARHI and PEG3 are the most frequently down-regulated in human ovarian cancers by loss of heterozygosity and promoter methylation. Cancer 112:1489-1502, 2008

6. Garzon MC, Huang JT, Enjolras O, Frieden IJ: Vascular malformations. Part II: associated syndromes. J Am Acad Dermatol 56:541-564, 2007

7. Golant A, Lou JE, Erol B, Gaynor JW, Low DW, Dormans JP: Pediatric osteoblastoma of the sternum: a new surgical technique for reconstruction after removal: case report and review of the literature. J Pediatr Orthop 24:319-322, 2004

8. Kaczurba M, Biedrzycki T, Buraczewska-Lipinska H, Dziadek T: [A case report of Gardner's syndrome with malignant transformation in one of the osseous lesions (osteoblastoma malignum).] Pol Przegl Radiol Med Nukl 40:213-217, 1976 (Polish)

9. Kan P, Schmidt MH: Osteoid osteoma and osteoblastoma of the spine. Neurosurg Clin N Am 19:65-70, 2008

10. Karunamurthy A, Pantanowitz L, Lepe JG, Reyes-Múgica M: Lethal outcomes in Klippel-Trenaunay syndrome. Pediatr Dev Pathol 16:337-342, 2013

11. Kohda T, Asai A, Kuroiwa Y, Kobayashi S, Aisaka K, Nagashima $\mathrm{G}$, et al: Tumour suppressor activity of human imprinted gene PEG3 in a glioma cell line. Genes Cells 6:237-247, 2001

12. Lucas DR, Unni KK, McLeod RA, O'Connor MI, Sim FH:
Osteoblastoma: clinicopathologic study of 306 cases. Hum Pathol 25:117-134, 1994

13. Mankin HJ, Hornicek FJ, Ortiz-Cruz E, Villafuerte J, Gebhardt MC: Aneurysmal bone cyst: a review of 150 patients. J Clin Oncol 23:6756-6762, 2005

14. McKusick VA, O’Neil MJF: Klippel-Trenaunay-Weber Syndrome. Online Mendelian Inheritance in Man. (http:// www.omim.org/entry/149000?search=klippel-trenaunayweber\%20syndrome\&highlight=syndromic\%20klippeltrenaunayweber\%20syndrome) [Accessed January 22, 2015]

15. Muzumdar D, Balasubramaniam S, Jhawar S, Goel A: Massive benign osteoblastoma of the suboccipital bone and foramen magnum region. Pediatr Neurosurg 46:232-237, 2010

16. O'Dwyer HM, Keogh CF, O'Connell JX, Munk PL: A case report of synchronous osteoblastoma and fibromatosis. Br J Radiol 81:e68-e71, 2008

17. Papaioannou G, Sebire NJ, McHugh K: Imaging of the unusual pediatric 'blastomas.' Cancer Imaging 9:1-11, 2009

18. Ropper AE, Cahill KS, Hanna JW, McCarthy EF, Gokaslan ZL, Chi JH: Primary vertebral tumors: a review of epidemiologic, histological, and imaging findings, Part I: benign tumors. Neurosurgery 69:1171-1180, 2011

19. Ye J, Liu L, Wu J, Wang S: Osteoblastoma of the rib with CT and MR imaging: a case report and literature review. World J Surg Oncol 10:49, 2012

\section{Author Contributions}

Conception and design: Henry, Wallace, Ignacio, Klugh. Acquisition of data: Wallace, Klugh, Gates. Analysis and interpretation of data: Henry, Wallace, Gates. Drafting the article: Henry, Wallace, Klugh, Gates. Critically revising the article: all authors. Reviewed submitted version of manuscript: all authors. Approved the final version of the manuscript on behalf of all authors: Henry. Administrative/technical/material support: Wallace, Gates.

\section{Correspondence}

Marion C. W. Henry, Naval Medical Center San Diego, Department of Surgery, 34800 Bob Wilson Dr., San Diego, CA 921345000. email: marion.henry@med.navy.mil. 